Vol. 72, N. ${ }^{\circ}$ II6 (noviembre 2020), 8I-IO2

ISSN-i I390-6380, ISSN-e 2697-3332 | https://doi.org/ro.29166/economia.v72iri6.2636

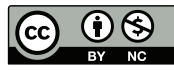

\title{
LA COOPERATIVA AGRARIA CAFETALERA PANGOA, EL COMERCIO JUSTO Y LOS CIRCUITOS ECONÓMICO SOLIDARIOS EN EL PERÚ
}

\author{
COOPERATIVA AGRARIA CAFETALERA PANGOA, FAIR TRADE AND SOLIDARITY \\ ECONOMIC CIRCUITS IN PERU
}

\author{
LUIS MONTOYA CANCHIS \\ Universidad Nacional Mayor de San Marcos (Perú)
}

Recepción del manuscrito: 1 de octubre de 2020

Aceptación versión final: 21 de noviembre de 2020

\begin{abstract}
RESUMEN El trabajo analiza las relaciones entre asociatividad cooperativa, comercio justo y sectores sociales como mujeres, jóvenes, pueblos originarios y el territorio, desplegadas por los pequeños productores de la Cooperativa Agraria Cafetalera Pangoa, de la Selva Central del Perú, como estrategias económico alternativas para enfrentar la marginalización generada por el mercado capitalista y profundizada por la aplicación de las políticas de liberalización de mercados desde la década del noventa. El análisis permite debatir sobre los circuitos económico-solidarios, relacionarlos con las estrategias económico-alternativas y la economía social y solidaria.
\end{abstract}

PALABRAS CLAVE Cooperativas de productores, cooperativas, mercados agrarios, agricultura y comercio internacional.

ABSTRACT The work analyzes the relationships between cooperative association, fair trade and social sectors such as women, youth, indigenous peoples and the territory, deployed by the small producers of the Cooperativa Agraria Cafetalera Pangoa, of the central Amazon region of Peru, as alternative economic strategies to face the marginalization generated by the capitalist market and deepened by the application of market liberalization policies since the 1990s. The analysis allows a debate on the solidarity economic circuits, relating them to the alternative economic strategies and the social and solidarity economy.

KEYWORDS Producer cooperatives, cooperatives, agricultural markets, agriculture and international trade.

JEL CODES J54, P13, Q13, Q17. 


\section{INTRODUCCIÓN}

Un documental estrenado el año 2019 titulado «Máxima», de la cineasta peruana Claudia Sparrow, muestra la lucha de la agricultora Máxima Acuña por defender su hogar frente a los intereses de la empresa minera Yanacocha. La férrea resistencia de Acuña, simboliza esfuerzos similares desplegados hoy por cientos de comunidades en todo el Perú, afectadas por conflictos eco-territoriales. También, hace evidente que los más humildes pueden desplegar estrategias para enfrentar al poder. Este artículo intenta reconstruir una historia de resistencia parecida. El largo recorrido desenvuelto por los pequeños productores de la Cooperativa Agraria Cafetalera Pangoa, una de las experiencias más emblemáticas del actual movimiento cooperativista peruano, ubicada entre la cordillera oriental de los Andes y la margen izquierda del río Ene, en la Selva Central del Perú.

Sus, aproximadamente, 690 socias y socios, conciben a la Madre Tierra como fuente de vida y logran conciliar su respeto por ella y un fuerte anclaje en el territorio, con la asociatividad cooperativa y el acceso al comercio justo, estrategias económico alternativas que, como se explicará más adelante, son fundamentales para el despliegue de su experiencia; pero también para su funcionamiento potencial como circuito económico solidario, porque - como dice Arcos (2018) - reúne condiciones para ser un espacio complejo de intercambio de servicios, bienes e incluso saberes que tienen como objeto, de una manera u otra, significarse como alternativas tangibles y reales al mercado capitalista en general (2018, p. 9). Es posible asumir, en este sentido, de manera preliminar - siguiendo a Coraggio (2011) - que su experiencia podría ser caracterizada como económico social y solidaria. ${ }^{2}$

Esto no supone necesariamente el establecimiento de relaciones armoniosas, todo lo contrario, ha expresado y expresa tensiones, conflictos abiertos y en muchos casos agudos, nada fáciles de resolver y mucho menos posibles de eludir. La pujanza y decisión de sus socias y socios desenvueltas desde su definición como pueblo solidario, ${ }^{3}$ expresada a través de la fundación de la cooperativa en 1977, permitió mancomunar sus esfuerzos y enfrentar conjuntamente problemas compartidos. ${ }^{4}$

Sus socias y socios han conseguido, además, apelando a la misma pujanza y decisión, vender su grano de café al mundo, a través de las redes del comercio justo. ${ }^{5}$ Esto le permitió adquirir activos en infraestructura valorizados en un aproximado de USD 1.400 .000 , realizar ventas brutas de alrededor de USD 4.500.000 anuales y recibir un total de USD 2.007.695 por la prima de comercio justo, un promedio de ciento cincuenta mil dólares anuales, desde el año 2003 en adelante, principalmente, por la venta de café. ${ }^{6}$

El contexto actual de crisis sanitaria, generado por la covid-19, afectó a la cooperativa y obligó a tomar medidas de prevención, como en muchas partes del mundo; pero no ha mellado su actividad ni dinamismo, porque la colocación de su producción de grano de café y cacao al comercio justo ha sido mantenida de manera constante. Ahora, incluso, la cooperativa ha tenido que comenzar a abastecer a un mercado local de nuevos compradores, residentes sobre todo en la ciudad de Lima, que requieren su café, tostado, molido y empacado, para ventas vía delivery. El artículo recurre a entrevistas realizadas con directivos, socias, socios y personal técnico de la cooperativa, así como a la revisión de fuentes secundarias. ${ }^{8}$ Estas incluyen documentos internos, informes de instituciones de apoyo, reportes censales y literatura especializada producida sobre esta experiencia y otras similares. ${ }^{9}$ 
La exposición está dividida en cuatro secciones: la primera, aborda el largo proceso de asociatividad cooperativa desenvuelta en Pangoa; la segunda, analiza la vinculación con el comercio justo; la tercera, indaga en las relaciones de la cooperativa con sectores sociales como mujeres, jóvenes, pueblos originarios y el territorio; y la cuarta, reflexiona a manera de conclusión sobre las estrategias económico-alternativas y los circuitos económico solidarios.

\section{LA ASOCIATIVIDAD COOPERATIVA PANGOA}

El 2 de octubre de 1977 es fundada la Cooperativa Agraria Cafetalera Pangoa, como resultado de la confluencia de tres factores: por un lado, la afirmación de una identidad territorial surgida desde el distrito de Pangoa en oposición a la capital de la provincia, la ciudad de Satipo; de otro, la demanda de asegurar que los pequeños productores cafetaleros pangoinos fueran los conductores y beneficiarios principales del movimiento y la organización cooperativista; y finalmente, la confluencia de intereses de profesionales o técnicos agrarios con los de pequeñas y pequeños productores cafetaleros. ${ }^{10}$

La identidad territorial forjada desde Pangoa emerge de la reivindicación de las poblaciones de colonas y colonos que migraron a este distrito y continuaron el proceso de colonización iniciado en el siglo xix y en particular el impulsado desde mediados del siglo xx, por las políticas de colonización del Estado republicano en el Perú. No se debe olvidar que estas políticas invisibilizaron a los pueblos originarios asháninka, amuesha y nomatsiguenga; pero alentaron la migración hacia los territorios de la Amazonía, de poblaciones andinas, costeñas y emigrantes.

Los colonos generaron una serie de necesidades y demandas hacia el Estado, las cuales canalizaron en más de un caso a través de la conformación de circunscripciones y municipalidades distritales que les permitieron negociar con el Estado recursos públicos. Este fue el caso del distrito de Pangoa, constituido inicialmente en 1962, como anexo del entonces distrito de Satipo, integrante en ese momento de la provincia de Jauja, región Junín. Luego, con su creación como distrito, en 1965, logra consolidar una circunscripción y una identidad territorial entre su población. La cual será la base de la emergencia de la reivindicación, de los pangoinos, a la que se hacía alusión.

Parece necesario llamar la atención sobre el peso que tendrá la producción cafetalera en la conformación de la identidad territorial. No es posible omitir que la vocación productiva del distrito de Pangoa es el café. No forjada recientemente, sino desde sus orígenes como circunscripción distrital. Son los cafetaleros los protagonistas de la creación del distrito y los impulsores de sus dinámicas económico territoriales. Por ello, es posible vincular el proceso de conformación de la identidad territorial, en este lugar, con la producción cafetalera.

Entonces, la idea de forjar una cooperativa propia de los pangoinos no era difícil que encontrara aceptación y reconocimiento, en la medida que alentaba o reforzaba esta identidad territorial, en especial, si era planteada como una reivindicación y en el marco de la oposición con los intereses de la capital de la provincia, la ciudad de Satipo. Sin embargo, este último asunto es una variable clave, pero no la única. Igualmente, es pertinente reconocer que los conflictos internos desplegados al interior de la Cooperativa Satipo, antecesora de la Cooperativa Agraria Cafetalera Pangoa, fueron otro factor que influyó y resultó determinante en la fundación de 
esta última. Es decir, no surge como resultado de algo externo o impuesto sino más bien del propio proceso interno desplegado al interior de la cooperativa.

Por un lado, la mayor parte del volumen de la producción de café acopiado por la Cooperativa Satipo estaba concentrado en el distrito de Pangoa. Su traslado hasta la capital de la provincia generaba sobre costos a los cafetaleros pangoinos, ubicados a una distancia larga y exigidos de recorrer un tramo dificultoso por el estado de las vías en ese momento. Estos sobrecostos los perjudicaban. De otro lado, el crecimiento de la cooperativa por un mayor número de asociados hizo cada vez más complicada la difusión de información, la comunicación oportuna y transparente; así como la participación activa de todos sus afiliados.

La desconfianza, indignación y percepción de beneficios diferenciados y desiguales, no era difícil que surgieran entre los cafetaleros pangoinos, al sentir que los excedentes generados por la cooperativa estaban concentrándose en manos de los cafetaleros satipeños, sumado a las tensiones que en mayor o menor medida eran desenvueltas entre dirigencia y socios de base.

Por último, y finalmente, la confluencia de intereses de profesionales o técnicos agrarios con los de los pequeños productores pangoinos representaría otro factor clave. Se enfatiza en esto porque el cooperativismo no constituye únicamente una forma de organización sustentada en dinámicas exclusivamente económicas. Posee un fuerte componente social, en la medida que está sustentado en relaciones sociales e imbuido de valores y apuestas morales y políticas, que también resultan determinantes para su impulso y afianzamiento. El rol de los profesionales y técnicos, y su relación con los pequeños productores, en este caso de Pangoa, son factores que canalizan este componente. Porque son ellos los que potencialmente pueden transmitir, no solo conocimientos de tipo especializado, sino además sensibilidades, imaginarios y sentidos de la realidad de tipo cultural y político; así como intereses y demandas.

La fundación de la cooperativa es seguida de un proceso de desenvolvimiento institucional muy activo e intenso. Expresado en dos asuntos principales: por un lado, una dinámica participativa de elección democrática de dirigentes con el concurso amplio de los socios de la cooperativa; y de otro, una tendencia creciente de aumento de la productividad, expresada en el acopio de café, orientado al mercado interno y que genera un beneficio directo a los pequeños productores al incrementar sus ingresos familiares. Este proceso muestra a su vez varios asuntos relacionados. El aumento del acopio fue generado gracias al aumento de la productividad, resultado del soporte técnico brindado por la cooperativa, lo cual hizo evidente de manera práctica ante los socios que el esfuerzo desplegado en su creación tenía sentido, porque permitía apreciar un beneficio concreto al haberla creado, legitimaba la idea de su organización y fortalecía también su institucionalidad.

Vinculado a lo anterior, un elemento clave será también el equipo técnico dedicado a brindar soporte, especialmente tecnológico. Estas labores las asumirá el Departamento Agrícola liderado por Esperanza Dionisio. Ella, ingeniera agrónoma formada en la Universidad Nacional Agraria La Molina, empezará a trabajar en la cooperativa en 1980. El desenvolvimiento institucional activo e intenso de los primeros años de la cooperativa, es interrumpido drásticamente por el contexto vivido entre mediados de los ochenta y los noventa, caracterizado por una profunda precariedad económica, social y política. La hiperinflación vertiginosa y la devaluación de la moneda, experimentadas a nivel del Perú; pero sobre todo la incontrolada espiral 
de violencia política, generada por grupos subversivos que apelan al uso del terrorismo y el sabotaje, junto a la represión indiscriminada de las fuerzas armadas, impactan de manera trágica en el distrito de Pangoa.

Es necesario anotar que el distrito de Pangoa y la provincia de Satipo, de la cual forma parte como se indicó anteriormente, están ubicados en el denominado Valle de los Ríos Apurímac, Ene y Mantaro (VRAEM), zona estratégica en el marco del proceso de violencia política vivido en el Perú, porque constituyó la zona de repliegue de Sendero Luminoso cuando el Estado, a través de las fuerzas armadas, inicia la represión y combate de la subversión en la región Ayacucho, donde es iniciada la violencia política.

La situación de violencia política provoca, en estos años, diversos asesinatos, desapariciones, secuestros, desplazamientos forzados y matanzas. Hechos terribles que en algunos casos provocaron el arrasamiento de poblaciones enteras. Las fosas comunes de Matzuriniari y Saigón en Alto Anapati, son evidencias monstruosas de la brutalidad de la violencia, las cuales serían conocidos solo luego de la entrega del Informe de la Comisión de la Verdad y Reconciliación en el 2003 y la labor de denuncia periodística realizada más recientemente por varios medios de comunicación.

Este cuadro trágico dificulta en general las actividades de la cooperativa y la de sus socios. La zozobra y el miedo, al final de cuentas, no generan condiciones propicias para el desenvolvimiento de actividades productivas. Tampoco para la gestión administrativa, la cual también se vio afectada de manera determinante, al producirse el traslado de la gerencia a la ciudad de Lima. Lo cual provocó críticas y cuestionamientos por los costos que representaba, su ausencia de Pangoa, la incomunicación y la falta de previsión en el caso de los robos sufridos por la cooperativa en estos años: el hurto de un vehículo en Lima y el asalto a un camión que transportaba una carga de café en la ruta a Satipo.

Las desavenencias fueron agudizándose y convirtiéndose cada vez más en conflictos abiertos entre socios y gerencia. La situación de la cooperativa a mediados de los noventa, como consecuencia, no era la mejor. Su dinamismo y cohesión institucional había sido perdido por el impacto del contexto. Su productividad también había resultado afectada, en gran medida, por el abandono del campo como resultado del desplazamiento forzado frente al temor generado por la violencia. Sumado a deudas acumuladas por la cooperativa que no pudo afrontar por sus problemas internos y porque su capacidad de abastecimiento de la demanda del mercado había resultado duramente afectada.

¿Qué hacer frente a este panorama? ¿Cómo enfrentarlo? ¿Por qué persistir en la idea de la cooperativa? Las respuestas a estas interrogantes parecen posibles de encontrar en dos elementos: por un lado, el arraigo territorial afianzado entre los pequeños productores de Pangoa, el cual había sido consolidado con los años luego de transcurridas varias décadas de la fundación de su distrito, a pesar del contexto de crisis vivido; y de otro, la necesidad de poseer una estrategia económica alternativa para enfrentar y superar sus problemas, realizar sus reivindicaciones y delinear un derrotero para su futuro. El testimonio de Julio Aysana parece aporta elementos para abordar lo primero. Él señala con perspicacia:

[E]s necesario recordar que no todos se fueron o pudieron irse, durante los años de la violencia política vivida en Pangoa. Muchos tuvimos que quedarnos, porque no podíamos irnos y lo único que podíamos hacer era pelear, luchar por nuestra tierra. ${ }^{11}$ 
El apelar a un «nosotros» basado en el arraigo con el territorio puede brindar seguridad en medio de una situación de incertidumbre y desorden, de precariedad y caos, como el vivido en los años de la violencia política. Parece que este elemento se activó en el marco de los padecimientos de los socios de la cooperativa, porque había logrado constituirse en un componente importante de su identidad colectiva, afianzado por el tiempo transcurrido desde la creación del distrito y convertido en punto de soporte firme para su defensa frente a la amenaza representada por los grupos subversivos y las fuerzas armadas.

Es innegable que el desplazamiento forzado afectó a un sector grande de la población de Pangoa, pero también otro sector igual de grande — como señala Aysana - tuvo que quedarse y enfrentar la situación. Es en este sector, desde nuestra perspectiva, donde la idea de arraigo territorial adquirió peso y determinación. Sin embargo, este elemento es complementado con el segundo: la necesidad de poseer una estrategia económica alternativa para enfrentar la situación de crisis vivida. Un primer dato a reconocer y no olvidar - apelando otra vez al testimonio de Aysana- es que la cooperativa no dejó de funcionar y a pesar de sus problemas siguió representando una garantía para los pequeños productores pangoinos, no solo por los servicios prestados - acceso al mercado, apoyo técnico, etc.- , sino porque era una de las pocas organizaciones que generaban confianza entre la población durante estos años.

Un segundo dato de mención necesaria es que el mercado capitalista no brindaba condiciones favorables para la inserción de los pequeños productores, porque la intermediación desenvuelta por los comerciantes continuaba representando la principal forma de esquilmarlos $y$, por ello, mantenerse asociados a través de la cooperativa era una garantía para obtener mejores precios y beneficios por la colocación de su producción de café; sumado al hecho que por no ser considerados sujetos de crédito, por la banca comercial, no contaban con otra garantía o respaldo para sus actividades productivas que la cooperativa.

Persistir en el esfuerzo de mantener la cooperativa era, por lo tanto, una apuesta colectiva compartida por más de un socio, en la medida que la forma de asociatividad que representaba respondía a su necesidad de acceso al mercado y de esta forma rompía con la intermediación de los comerciantes locales. Esta situación convierte la asociatividad, desenvuelta a través de la cooperativa, en una estrategia económico-alternativa para los pequeños productores de Pangoa. Su carácter alternativo —-siguiendo la reflexión de Montoya, Alva, Carcelén, Pérez, Cardeña (2018) - radica en la racionalidad existente detrás de las relaciones que permiten su desenvolvimiento, basadas en lo fundamental en la solidaridad, la cooperación, la reciprocidad, diferente a la del mercado capitalista, interesada en el lucro y la ganancia; pero que no logra ser reemplazada, sino que convive con ella y establece, en más de un caso, relaciones de tensión (2018, p. 5).

Persistir en la cooperativa, en otras palabras, era una estrategia necesaria, para los pequeños productores, sin la cual no hubieran podido lograr su inserción en el mercado capitalista en términos más convenientes y beneficiosos, así como cubrir sus necesidades de generación de ingresos; su carácter alternativo radicaba en apelar a una racionalidad que, sin reemplazar a la del mercado capitalista, entraba en tensión con él por basarse en la solidaridad, la cooperación, la reciprocidad entre sus socias y socios. Sin embargo, persistir en el esfuerzo de mantener la cooperativa exigió a sus afiliados definir cómo remontar la situación derivada de la crisis. El punto de inflexión parece radicó en la decisión de 
Figura 1. Cooperativa Agraria Cafetalera Pangoa: producción vendida 2003-2018



recurrir a una vieja amiga, conocida bien por todos en la cooperativa, poseedora de un carisma frío y un conocimiento consistente, que les hizo generar la confianza suficiente para creer que les permitiría enfrentar y resolver sus varios y graves problemas. Esa vieja amiga era la ingeniería Esperanza Dionisio o simplemente, como comenzaron a llamarla de manera coloquial, la «ingeniera».

Ella asume la gerencia, entre fines de 1996 y comienzos de 1997, porque sus compromisos laborales previos no le permitieron asumir inmediatamente el cargo. Los socios toman la decisión porque consideran que una mujer podía representar mejor los valores de honestidad, empuje y perseverancia que la cooperativa requería en ese momento. ${ }^{12}$

Las deudas acumuladas fueron una de las primeras y principales preocupaciones de Dionisio. Una de ellas, la contraída con coINCA, ascendía a noventa mil dólares. La cual en lugar de convertirse en una amenaza se volvió una oportunidad, porque animó la solicitud a los socios de la entrega de dos 
sacos de café en donación por única vez para, con el resultado de su venta, poder cubrir la deuda existente. La respuesta fue unánime de parte de todos ellos y 350 socios realizaron la donación. Esto permitió cancelar la deuda y renegociar nuevos préstamos con otras entidades financieras. ${ }^{13}$

Dionisio estudia, además, el caso de la Cooperativa La Florida, una emblemática representante del movimiento cooperativista de la Selva Central, porque había tenido conocimiento que vendía su producción de grano de café a un mejor precio. Dionisio devela, gracias a su indagación, la razón: su producción era adquirida a nivel global a través de las redes de comercio justo. Este descubrimiento le permite avizorar una importante oportunidad para la cooperativa, que no podía desaprovecharse desde su punto de vista, porque el comercio justo brindaba grandes oportunidades para colocar su producción, sobre todo considerando que sería obtenido un precio mayor por la misma.

No es arbitrario además mencionar que el contexto a fines de los noventa no era el mejor, si bien la violencia política había sido mitigada y un clima de mayor tranquilidad era compartido en el conjunto del Perú, la aplicación de las políticas de liberalización de mercados, desde comienzos de los noventa, habían provocado un repliegue de la presencia del Estado y una recesión económica de fuerte impacto en los pequeños productores. Dionisio no podía, en este contexto, darse el lujo de perder oportunidades y sin demora concentró su actividad en lograr la primera venta al comercio justo, la cual logra realizar en 1998, gracias al respaldo de una carta fianza por cincuenta mil dólares otorgada por sos FAIM, un organismo no gubernamental de Bélgica, especializado en trabajar con campesinos de América Latina y África.

Un aspecto determinante, según ella, fue comprender que la naturaleza del comercio justo no consistía solo es ser una oportunidad de negocio o comercial, sino más bien en constituir un movimiento sustentado en principios similares a los del cooperativismo y donde enarbolar la búsqueda de una economía basada en el consumo ético y la justicia en el comercio internacional entre pequeños productores y compradores, eran aspectos fundamentales.

$\mathrm{Al}$ año siguiente, en 1999, la cooperativa presenta la solicitud para recibir la certificación de comercio justo ante Fairtrade Labelling Organizations International (FLO) y recibe la visita de inspectores externos de esta entidad. El 2001, lograda la certificación, la cooperativa empieza a gestionar la colocación de su producción a través de estas redes. Sin embargo, es desde el 2003 que la cooperativa recién logra vender su producción a FLO. Ese año coloca 1013 quintales de grano de café orgánico por un monto aproximado de USD 149.00o. Lo cual representa el $12 \%$ del total de su producción vendida en ese año. ${ }^{14}$

A pesar de representar un porcentaje pequeño del total de sus ventas, la producción vendida a FLO, permite a la cooperativa obtener un mejor precio por el quintal de grano de café orgánico, comparado con el recibido en los mercados locales y nacionales o el mercado orgánico. El comercio justo pagaba ese año USD 147 el quintal, los mercados locales y nacionales USD 57,6 y el mercado orgánico USD $74,8 .{ }^{15}$ Además, la cooperativa capitaliza la prima de comercio justo al recibir USD 70.369. Cantidad distribuida en reintegros dados a los socios, USD 49.258, 70\% del total; inversiones USD 14.074, 20\% del total; fondo de salud USD 3518, 5\% del total; $y$ fondo educativo usD $3518,5 \%$ del total. ${ }^{16}$

No se quiere extender en la presentación de datos sobre la producción vendida o la prima de comercio justo obtenida. Asuntos sobre los cuales se tratará más adelante con mayor detalle. 
Figura 2. Cooperativa Agraria Cafetalera Pangoa: acumulativo total de prima de comercio justo 2003-2016

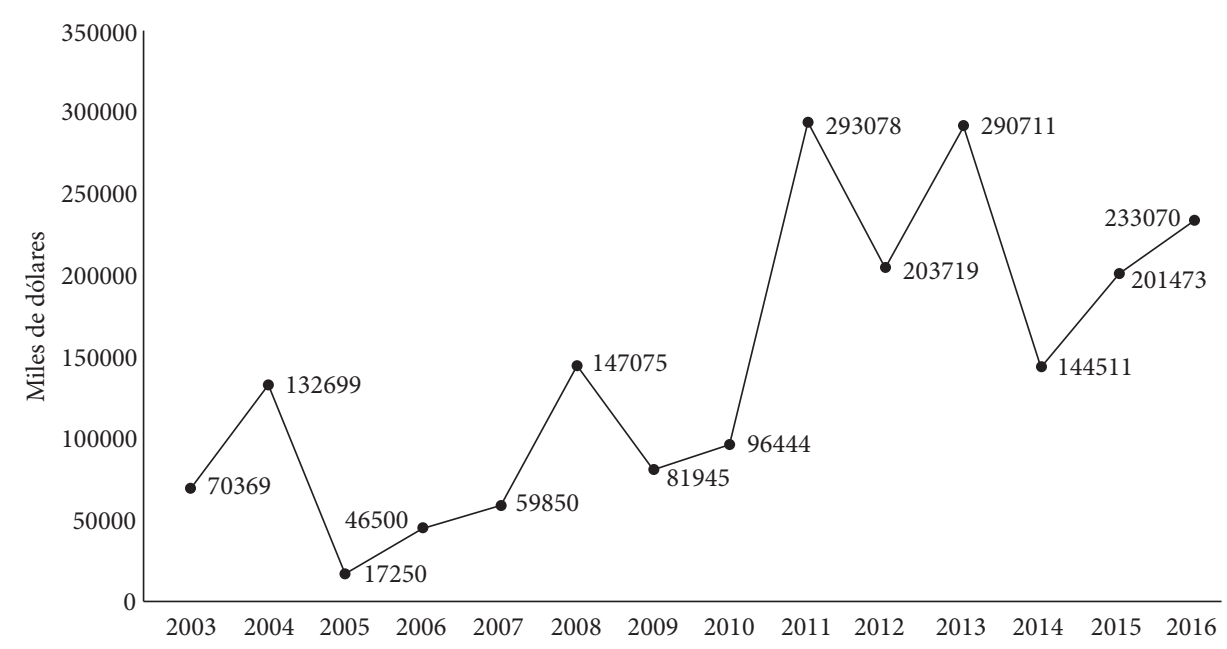

Lo que se quiere resaltar más bien como, poco a poco, gracias a la decisión de Dionisio, el cariño de los socios por su cooperativa y las oportunidades que el comercio justo abrió, la cooperativa comenzó a generar ingresos que le permitieron cubrir sus deudas, abrir un nuevo mercado alternativo que le facilitó recuperar su oferta productiva centrada en la venta de grano de café orgánico y resurgir paulatinamente. Este proceso seguirá con los años e incluso se expresará en la diversificación de sus productos gracias a la incorporación del cacao y la miel de abeja. Los cuales, si bien no serán vendidos, en el mismo volumen que el café y exclusivamente al mercado de comercio justo, su colocación en mercados locales, nacionales y, sobre todo, orgánico, representará otra fuente de ingresos.

\section{EL COMERCIO JUSTO Y PANGOA}

La cooperativa, como se indicó anteriormente, posee la certificación brindada por FLO, organización con la que establece el primer vínculo con las redes de comercio justo. ${ }^{17}$ Las ventas realizadas, en el periodo 2003 y 2018, evidencian con claridad el proceso de evolución creciente de la colocación de la producción de grano de café efectuada por parte de la cooperativa. Las cifras muestran que el volumen de producción vendido pasa de 1013 quintales en $2003,12 \%$ del total de su producción vendida ese año; a 12.349 quintales en 2018, 54\% del total de su producción vendida.$^{18}$ Durante el mismo periodo la producción vendida a mercados locales y nacionales capitalistas pasa de 6896 quintales en 2003, 83\% del total de la producción vendida ese año; a 7521 quintales en $2018,33 \%$ del total de su producción vendida.

Por su parte, la producción colocada en el mercado orgánico evoluciona de 375 quintales en 2003, 5\% del total de su producción vendida ese año; a 3021 quintales en 2018, 13\% del total de 
su producción vendida. La figura presentada a continuación, permite registrar la evolución de la producción vendida al comercio justo, mercados locales y nacionales capitalistas, así como orgánico, entre los años 2003 y 2018 (ver Figura 1).

El crecimiento de la venta al comercio justo obedece en gran medida al beneficio diferencial obtenido de los precios. El 2003 el comercio justo pagó USD 147 el quintal de grano de café orgánico, los mercados locales y nacionales capitalistas USD 57,6 y el mercado orgánico USD 74,8. El 2018 el comercio justo pagó USD 206,9 por el quintal de grano de café orgánico y USD 165,9 por quintal de café convencional; los mercados locales y nacionales capitalistas pagaron USD 119,6; y el orgánico USD 196,7.19

La cooperativa obtiene, el 2003, por la venta de su producción de grano de café orgánico al comercio justo, un aproximado de USD 149.00o; el mismo año, la venta de grano de café convencional a mercados locales y nacionales capitalistas genera aproximadamente USD 397.210; y la venta a mercado orgánico un monto aproximado de USD 28.050. El 2018 la venta de grano de café orgánico y convencional al comercio justo, por parte de la cooperativa, genera un ingreso aproximado de USD 2.436.518,1; la venta de grano de café convencional a mercados locales y nacionales capitalistas produce un ingreso de aproximadamente de USD 899.511,6; y la venta a mercado orgánico un aproximado de USD 594.230,7. El diferencial a favor de los pequeños productores, obtenido del precio ofrecido por el comercio justo, no solo es el único beneficio. La prima de comercio justo es otro incentivo determinante. Este estímulo es recibido por los pequeños productores como parte de las transacciones desenvueltas en el marco del mismo.

La acumulación total de la prima de comercio justo, en el periodo 2003 y 2016, en el caso de la cooperativa confirma que su evolución ha ido en incremento, no sin oscilaciones; pero mostrando un crecimiento ostensible. Las cifras permiten apreciar como esta variable pasa de USD 70.369 en 2003 a USD 233.070 en 2016 y evidencia un incremento de tres veces. ${ }^{20}$ Esta figura permite apreciar su desenvolvimiento (ver Figura 2).

Se anotó que la suma del acumulativo de la prima de comercio justo en el periodo analizado, 2003 y 2016, alcanza los USD 2.007.695. Cantidad que representa aproximadamente, ciento cincuenta mil dólares en promedio por año, desde el año 2003 en adelante. No solo la acumulación de la prima de comercio justo puede servir como una variable para medir el peso e interés generado entre los pequeños productores de la cooperativa. Su distribución también ha sido clave. La cual es decidida anualmente en asamblea de y socios, así como de manera democrática directa.

La información disponible en la figura tres permite apreciar que en el periodo 2003 y 2016, USD 767.131, 38\%, fueron empleados en reintegros para los socios; USD $375.772,19 \%$, en inversiones; USD 264.144, 13\%, estuvieron destinados a pago en acopio de café para los socios; USD 133.590, 7\%, en renovación de cafetales; USD 96.374, 5\%, en el fondo educativo de la cooperativa dirigido a socios e hijos de ellos; USD 71.105, 4\% en el fondo de salud; USD $68.769,3 \%$, en productividad; USD $67.676,3 \%$, fueron destinados a financiar las actividades del comité educativo; USD 55.522, $3 \%$, en el fondo de vivienda saludable; USD $49.522,2 \%$, en el proceso de secado de café; USD 48.106, 2\%, en la planta de beneficio húmedo ( $\mathrm{PBH}$ ), necesaria en la estandarización de la humedad del café de los socios; USD 9983, 1\%, en gastos de sepelio (ver Figura 3). 
Figura 3. Cooperativa Agraria Cafetalera Pangoa:

distribución del total de prima del comercio justo 2003-2016

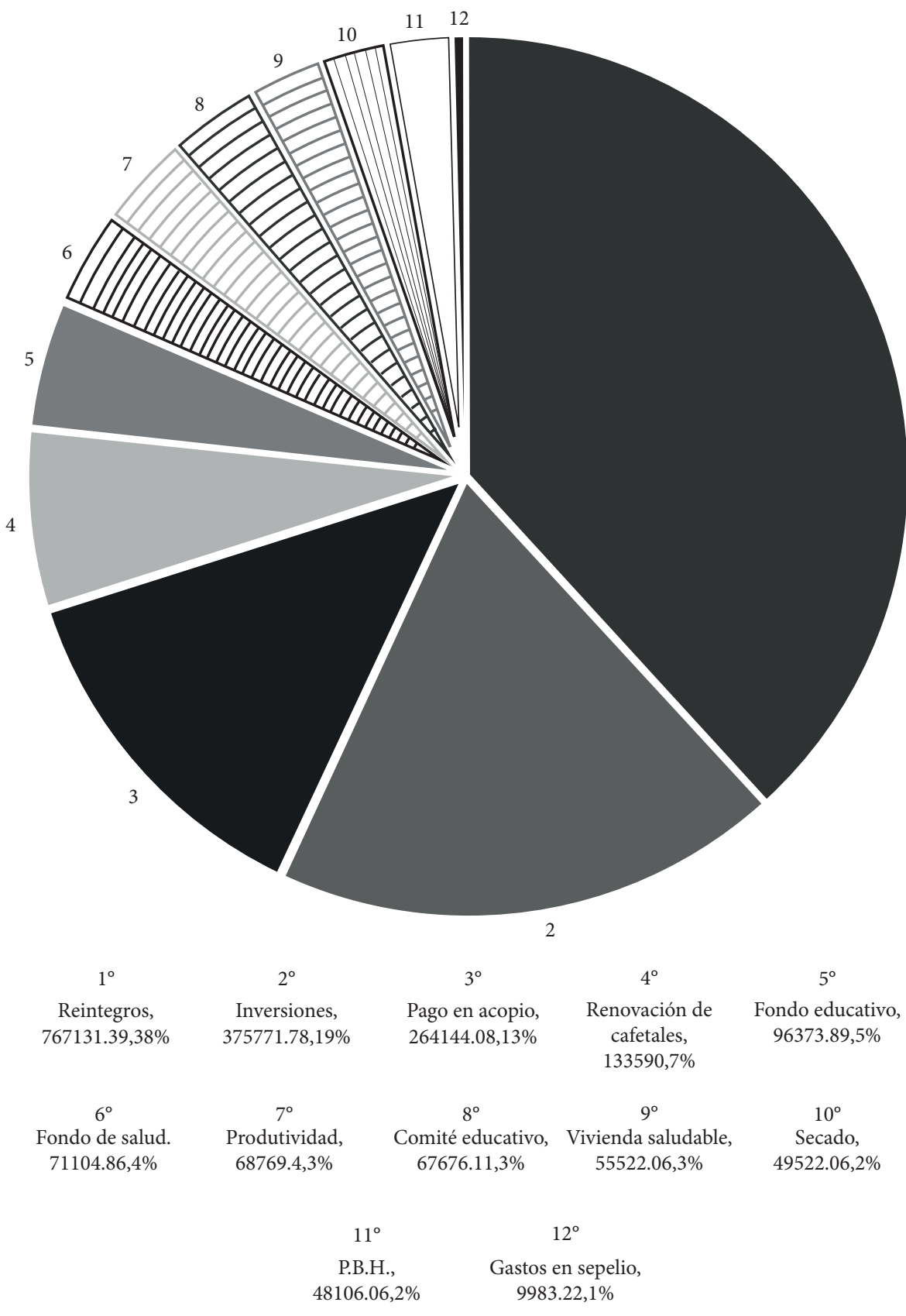


La evolución experimentada en cada uno de estos rubros, durante el periodo analizado, permite poseer una perspectiva más precisa sobre su desenvolvimiento. Se presenta la información dividida en dos tipos de beneficios: beneficios directos o individuales y beneficios indirectos o colectivos, referidos a necesidades e intereses compartidos por todos los socios.

Se expone a continuación el desenvolvimiento experimentado por cada rubro en el marco de los dos tipos de beneficios indicados: la tabla 1 muestra cómo los reintegros pasan de USD 49.258, en 2003, a USD 131.252, en 2015. Experimentan, por lo tanto, un aumento de dos veces y media en el periodo examinado. Los socios de la cooperativa han recibido en promedio por reintegros, aproximadamente, alrededor de mil dólares por persona, gracias a la prima de comercio justo entre 2003 y 2015. Cifra que si bien no es elevada ha representado otro ingreso para ellos, así como para sus familias, y que no hubieran recibido en el sistema comercial (ver Tabla 1).

El pago en acopio transita de USD 12.563, en 2004, a USD 64.184, en 2015, experimenta, por lo tanto, un incremento de cinco veces. Este rubro registra montos solo en 2004, 2013, 2014 y 2015. La renovación de cafetales evoluciona de USD 22.875, en 2007, a USD 70.774, en 2011, muestra, por lo tanto, un aumento de casi tres veces. Este rubro solo es implementado entre los años 2007 y 2011.

Por su parte, los beneficios indirectos o colectivos, mostrados en la tabla 2, referidos a inversiones e infraestructura, siguen el siguiente desenvolvimiento: las inversiones pasan de USD 14.074, en 2003, a USD 85.000, en 2016. Incrementan su volumen en seis veces. Este rubro muestra particular interés porque permite apreciar que los socios decidieron dedicar una parte de la prima de comercio justo a diversificar su actividad económica en inversiones no restringidas a la actividad productiva de la cooperativa, sino explorar otros sectores como comercio y servicios donde principalmente fueron dirigidas las inversiones (ver Tabla 2).

El rubro de productividad registra solo un monto de USD 68.769 en el 2016. Éste fue usado como estímulo para premiar el aumento de la producción de los socios. El rubro de secado evoluciona de USD 14.708, en 2008, a USD 10.000, en 2016. Es decir, disminuye ligeramente. Igual reducción ocurre con el rubro dedicado a la $\mathrm{PBH}$, la cual registra un monto de USD 14.708, en 2008, y de USD 10.000, en 2016.

La tabla 3 presenta los beneficios indirectos o colectivos referidos a inversiones sociales, desenvueltos de la siguiente forma: el fondo de salud, el cual brinda un apoyo a socios ante enfermedades de alto costo de tratamiento o y desatención de la cobertura del servicio de salud pública o la seguridad social, pasa de USD 3518, en 2003, a USD 10.000, en 2016. Es decir, crece en casi tres veces. El fondo permite, de acuerdo a su reglamento, la atención del socio, el cónyuge o pareja, así como de sus hijos. 70 socios son atendidos por año, aproximadamente, desde que fue implementado ${ }^{21}$ (ver Tabla 3).

De otro lado, el fondo educativo, dedicado a dar soporte a estudios realizados sobre todo por hijas e hijos de socias y socios con limitaciones económicas para costearlos, transita de USD 3518, en 2003, a USD 20.000, en 2016. Lo cual representa un incremento de casi seis veces. El fondo ha atendido hasta el momento a 26 estudiantes y ha logrado que 19 concluyan sus estudios universitarios. El fondo, según su reglamento, obliga a los que lo reciben a devolver los recursos entregados. De los 26 estudiantes beneficiados con el fondo, 11 han terminado sus estudios y han devuelto los recursos asignados, 8 han terminado y están pagando con retraso y 7 están estudiando actualmente. ${ }^{22}$ 
Tabla 1. Cooperativa Agraria Cafetalera Pangoa: acumulativo prima de comercio justo en reintegros, pago en acopio y renovación de cafetales, 2003-2015

\begin{tabular}{lccc}
\hline Año & Reintegros & Pago en acopio & Renovación de cafetales \\
\hline 2003 & 49.258 & & \\
\hline 2004 & 92.889 & 12.563 & \\
\hline 2005 & & & 22.875 \\
\hline 2006 & 11.812 & & 20.474 \\
\hline 2007 & 11.700 & & 11.751 \\
\hline 2008 & & & 7.716 \\
\hline 2009 & 16.651 & & 70.774 \\
\hline 2010 & 34.705 & & \\
\hline 2011 & & & 153.096 \\
\hline 2012 & 195.973 & 34.301 & 133.590 \\
\hline 2014 & 114.876 & 64.184 & \\
\hline 2015 & 108.014 & 264.144 & \\
\hline Total & 131.252 & & \\
\hline
\end{tabular}

Es pertinente anotar también que el comité de educación pasa de recibir USD 7354, en 2008, a USD 11.300, en 2016, lo cual representa un incremento de más de la mitad de los recursos que recibía inicialmente. Este comité está integrado por socios elegidos para dirigir el conjunto de actividades educativas desenvueltas por la cooperativa, como la Escuela de líderes, y recibe apoyo del área de educación una instancia técnica o administrativa.

Junto a estos rubros, el de vivienda saludable, dedicado a lograr mejores niveles de habitabilidad en las residencias de socios y socias en armonía con el ambiente, registra también un incremento en su inversión. Este rubro evoluciona favorablemente, en veinte por ciento, al pasar de USD 14.708, en 2008, a USD 18.000, en 2016. El número de socios atendidas fue 37 y generó un beneficio indirecto en alrededor de 200 personas, ${ }^{23}$ al mejorar de manera ostensible sus viviendas. Este rubro permitió, también, junto a proyectos trabajados con agencias de cooperación internacional aliadas de la cooperativa, la reforestación de un millón de árboles. ${ }^{24}$

Igualmente, un rubro que mereció atención fue el de gastos de sepelio, dirigido a brindar apoyo a socias y socios con dificultades, para afrontar los costos del fallecimiento de familiares. El rubro fue implementado por cinco años, entre 2008 y 2011 y el 2016, periodo en el que pasa de USD 2942 a USD 2831.

No es difícil deducir que la inversión en fondos sociales, como los de salud y educación; la dedicación de recursos para lograr viviendas saludables, el financiamiento de las actividades del comité de educación o los gastos en la atención de un asunto sensible para las familias como el sepelio, evidencian el impacto de la prima de comercio justo en la vida cotidiana de los socios de la cooperativa. Es decir, no solo el comercio justo constituye una oportunidad para colocar la producción de los pequeños productores, sino además ha generado una oferta importante de servicios sociales para ellos — como lo hacen notar algunas y algunos 
entrevistados beneficiados con los mismos-, sustentado en el uso de la prima, directamente, relacionados con su cotidiano, individual y familiar. ${ }^{25}$

Si bien el incremento de la inversión no asegura por sí misma mejoras efectivas en las condiciones de vida de las personas, parece pertinente registrar estas inversiones sociales como una evidencia del peso que las personas adquiere en las políticas de comercio justo y como una variable propia del entorno que genera oportunidades y condiciones favorables para el fortalecimiento de capacidades en los socios de la cooperativa y sus familiares.

La información levantada por Chagua y Zuñiga (2018), en base a un abordaje cuantitativo, una muestra de 208 productoras y productores encuestados, confirma:

[S]e ha observado que gracias a la implementación del comercio justo se ha podido mejorar la calidad de vida y de la producción de los cultivos de muchas personas que participan de este tipo transacciones, es decir a nivel social-familiar y técnico-productivo. (Chagua y Zuñiga, 2018, p. 122)

No es posible negar los impactos positivos del comercio justo, sin embargo, es pertinente admitir que el sistema no es perfecto. Keisling (2013), señala entre otros problemas, los pequeños productores no disfrutan de los precios íntegros recibidos en la venta de sus productos, porque las cooperativas a las cuales están afiliadas actúan como intermediarios de la cadena de producción y hacen deducciones hasta que el productor se queda con ingresos reducidos (Keisling, 2013, p. 40).

Este problema no aparece en el caso de la Cooperativa Agraria Cafetalera Pangoa. Un elemento que parece central y determinante para que este y otros problemas no aparezcan es la fuerte cohesión institucional lograda, basada en el control democrático directo, a través de las asambleas y la rotación anual de cargos de dirigentes, lograda por los socios de la cooperativa. Esto facilita que disfruten de los beneficios íntegros recibidos de la venta de sus productos y evita que la cooperativa actúe como intermediaria de la cadena de producción y termine generando beneficios no reconocidos por todos como necesarios. Es importante anotar la fuerte identificación lograda entre un sector mayoritario de socios con la cooperativa, factor determinante también de este tipo de cohesión institucional basado en el control democrático directo.

\section{LAS MUJERES, LOS JOVENES, LOS PUEBLOS ORIGINARIOS Y EL TERRITORIO}

La cooperativa, como se propuso en la introducción, puede ser caracterizada como una experiencia económico social y solidaria, por ello, parece central no reducir nuestra mirada a las ganancias monetarias y hacer visible las vinculaciones establecidas entre ella y sectores sociales como mujeres, jóvenes, pueblos originarios, así como con el territorio de la Selva Central. Las mujeres constituyen un sector muy importante dentro de la cooperativa, 522 socios son varones, $76 \%$ del total; y 168 socias son mujeres, $24 \%$ del total. Es decir, ocho de cada diez socios son varones y dos de cada diez son mujeres; pero no debe perderse de vista, igualmente, a las mujeres que son esposas, hijas o familiares de los socios. Ellas están organizadas, al interior de la cooperativa, en el Comité de Desarrollo la Mujer (CODEMU). Es necesario anotar que el CODEMU no solo representa una instancia constituida y reconocida en el organigrama 
Tabla 2. Cooperativa Agraria Cafetalera Pangoa: acumulativo prima de comercio justo en inversiones, productividad, secado, $\mathrm{PBH}, 2003-2016$

\begin{tabular}{|c|c|c|c|c|}
\hline Año & Inversiones & Productividad & Secado & $\mathrm{PBH}$ \\
\hline 2003 & 14.074 & & & \\
\hline 2004 & 19.285 & & & \\
\hline \multicolumn{5}{|l|}{2005} \\
\hline 2006 & 20.973 & & & \\
\hline 2007 & 2.400 & & & \\
\hline 2008 & 44.123 & & 14.708 & 14.708 \\
\hline 2009 & 13.062 & & 6.531 & 6.531 \\
\hline 2010 & 29.415 & & 3.376 & 3.376 \\
\hline 2011 & 138.851 & & 14.908 & 13.492 \\
\hline \multicolumn{5}{|l|}{2012} \\
\hline 2013 & 8.589 & & & \\
\hline \multicolumn{5}{|l|}{2014} \\
\hline \multicolumn{5}{|l|}{2015} \\
\hline 2016 & 85.000 & 68.769 & 10.000 & 10.000 \\
\hline Total & 375.772 & 68.769 & 49.522 & 48.106 \\
\hline
\end{tabular}

de la cooperativa, es sobre todo una experiencia organizativa y de participación protagónica femenina — como señala Pujay (2017)—:

[C]reada en el año 1999, su gestión es desenvuelta especialmente por mujeres, sobre todo porque asumen los cargos principales de su conducción: presidencia, vicepresidencia y secretaria. Desde sus inicios, el CODEMu incorporó en su plan de trabajo la estrategia de microcréditos como su principal actividad. (2017, p. 154)

El CODEMU surge en gran medida — como la indagación de Pujay consigna- por programas y proyectos implementados por organismos de cooperación internacional como la Sociedad de Cooperación para el Desarrollo Internacional (socodevi), además del apoyo de la propia cooperativa; y logra afianzarse en el marco de las políticas de comercio justo.

Los jóvenes, por su parte, están organizados a través del Comité de Jóvenes (CODEJ). El CODEJ es otra instancia importante, por haber abierto un mecanismo de participación para los jóvenes de la cooperativa, que articula alrededor de 50 jóvenes aproximadamente. Rolando Aparco, expresidente del consejo de administración y del coDEJ, testimonia la importancia que tuvo en su vida personal:

El CODEJ es importante porque permite a los socios jóvenes y a los hijos de los socios participar de la vida de la cooperativa. Un ejemplo fue lo que viví. Al provenir de Angaraes, Huancavelica, no fue fácil para mí insertarme en la vida de Pangoa. No era mi mundo, las costumbres eran diferentes [...] cuando me hice socio de la cooperativa me di cuenta que el trabajo con jóvenes era importante y me abrió oportunidades. El 2012 fue creado el CODEJ y fui elegido como presidente. El apoyo brindado por instituciones como Veco Andino animó a los socios de la 
cooperativa a crear este comité [...] el comercio justo afianzó toda la línea de trabajo con jóvenes, no sólo en la cooperativa, sino nos hizo ver más amplio al relacionarnos con otros jóvenes de otras cooperativas, de la Selva Central y fuera de ella, a nivel del Perú y otros países. ${ }^{26}$

Los pueblos originarios representan otro sector social con el cual la cooperativa está vinculada. 541 socios y socias, $78 \%$, son colonos de origen andino, en especial, de regiones como Junín, Huancavelica, Ayacucho; y 149, 22\%, son de pueblos originarios amazónicos, principalmente, nomatsiguenga y en menor medida ashaninka. Es decir, ocho de cada diez son colonos y dos de cada diez pertenecen a un pueblo originario. Este origen étnico diverso ha planteado desafíos para la organización y el fortalecimiento institucional de la cooperativa, porque supone el manejo de un enfoque intercultural, a través del cual poner en diálogo las diferentes tradiciones culturales presentes entre los socios de la cooperativa. La mayoría de socios de pueblos originarios están organizados en el comité zonal 7, uno de los 17 que posee la cooperativa y que fueron establecidos como una estrategia de organización interna para ligarse al territorio. La organización de los socios nomatsiguenga y ashaninka ha permitido, entre otros procesos, el desenvolvimiento de relaciones sociales y culturales diversas. Un ejemplo es el intercambio de saberes amazónicos y andinos generado a partir de la producción orgánica de miel. Esta surge de la iniciativa del comité 7 y ha permitido a la cooperativa ofertar miel, como un nuevo producto, surgido del aporte nomatsiguenga y ashaninka, así como del diálogo intercultural amazónico y andino.

La relación con el territorio es otro asunto sensible a considerar y con el cual la cooperativa desenvuelve, igualmente, una variedad de vínculos. Un punto de partida para comprender la magnitud de este conjunto de vinculaciones son las transformaciones experimentadas en las relaciones entre los socios de la cooperativa, como poblaciones asentadas, y el bosque, las cuales han experimentado cambios acelerados resultado — como se mencionó antes- de la colonización como política animada desde el Estado. Sin embargo, este asunto merece examinarse no solo desde una perspectiva histórica, sino también desde una lectura sistémica, porque como lo han señalado Sancho y Calderón (2013), para el caso de las experiencias de producción de pueblos originarios de la Selva Central:

Los cultivos estacionales e intensivos, como el cacao y el café, plantean la cuestión de la relación directa entre su expansión y la degradación del bosque. Abrir nuevas áreas significa empobrecer, cuando no desaparecer, la capa boscosa. En definitiva, un bosque en retroceso [...]; esta pérdida no significa una preocupación paisajística o mera ternura ecológica, sino una alerta que podría poner en jaque el mantenimiento y la proliferación de ecosistemas que también son vitales [...]. Pero al mismo tiempo, y con el mismo sentido de la realidad, somos conscientes de que precisamente este modo de vida no es ni hermético, ni estático, ni falto de recursos para reinventar, negociar y adoptar, como demuestran las familias en su día a día, nuevos estilos de relación con su hábitat. Y con ese refundarse no pierde, en nuestra opinión, autenticidad. (2013, p. 73)

Lo señalado por Sancho y Calderón parece adquiere mayores niveles de alerta, en el caso de la actividad desenvuelta por los socios de la cooperativa, porque en ella no solo confluyen socios de pueblos originarios, sino además colonos de origen andino. Situación que hace mucho 
Tabla 3. Cooperativa Agraria Cafetalera Pangoa: Acumulativo prima de comercio justo en fondo de salud, fondo educativo, vivienda saludable, gastos de sepelio, comité de educación, 2003-2016

\begin{tabular}{|c|c|c|c|c|c|}
\hline Año & $\begin{array}{l}\text { Fondo de } \\
\text { salud }\end{array}$ & $\begin{array}{c}\text { Fondo } \\
\text { educativo }\end{array}$ & $\begin{array}{l}\text { Vivienda } \\
\text { saludable }\end{array}$ & $\begin{array}{l}\text { Gastos de } \\
\text { sepelio }\end{array}$ & $\begin{array}{c}\text { Comité } \\
\text { de educación }\end{array}$ \\
\hline 2003 & 3.518 & 3.518 & & & \\
\hline 2004 & 3.981 & 3.981 & & & \\
\hline 2005 & 8.625 & 8.625 & & & \\
\hline 2006 & 6.858 & 6.858 & & & \\
\hline 2007 & 11.438 & 11.438 & & & \\
\hline 2008 & 11.031 & 11.031 & 14.708 & 2.942 & 7.354 \\
\hline 2009 & 4.900 & 4.900 & 6.531 & 1.303 & 9.784 \\
\hline 2010 & 3.376 & 3.376 & 3.376 & 2.908 & 4.823 \\
\hline 2011 & 5.342 & 22.648 & 12.908 & 2.831 & 11.324 \\
\hline 2012 & & & & & 7.746 \\
\hline 2013 & & & & & 9.150 \\
\hline 2014 & & & & & 2.195 \\
\hline 2015 & 2.037 & & & & 4.000 \\
\hline 2016 & 10.000 & 20.000 & 18.000 & & 11.300 \\
\hline Total & 71.105 & 96.374 & 55.522 & 9.983 & 67.676 \\
\hline
\end{tabular}

más complejo definir cuál será el derrotero final o la característica principal que asumirá el entorno donde estas actividades productivas son desenvueltas. Su prioridad, permítase anotarlo, no radica solo en la pérdida o manteniendo de la autenticidad de las poblaciones asentadas sino principalmente - como estos mismos autores mencionan al inicio de la cita- en la sostenibilidad de los ecosistemas involucrados y con los cuales estas poblaciones desenvuelven interacciones.

La sostenibilidad es puesta en tensión por el cultivo del café y cacao, implementados de manera estacional e intensiva, y que muchas veces no responden a prácticas enmarcadas en sistemas agroforestales certificados y ambientalmente sostenibles. Justamente, por ello, la importancia de lograr el convencimiento del conjunto de socios y socias de la cooperativa de asumir estos sistemas como parte de su actividad productiva.

\section{CONCLUSIÓN: CIRCUITOS ECONÓMICO SOLIDARIOS Y ESTRATEGIAS ECONÓMICO ALTERNATIVAS}

El análisis de la experiencia de la Cooperativa Agraria Cafetalera Pangoa permite apreciar que los pequeños productores cafetaleros de la Selva Central del Perú, determinados por la necesidad de colocar su producción y enfrentar la marginalización del mercado capitalista, al ser esquilmados por la voracidad de los comerciantes intermediarios, así como motivados por su decisión audaz y pujante de exportar, recurrieron a la asociatividad cooperativa con el propósito de afianzar su organización, mejorar su productividad y fortalecer su posicionamiento en 
el territorio; pero, también, accedieron al comercio justo, para mejorar sus ingresos y conectarse con redes de comercialización y consumo de sus productos, así como animar una serie de relaciones con sectores sociales como mujeres, jóvenes, pueblos originarios y su territorio, desde su experiencia de economía social y solidaria. Sin embargo, estas estrategias en ningún caso dejaron del lado al mercado capitalista, sino que más bien fueron empleadas, en tensión con él y sin lograr suplirlo.

Esto permite deducir y sustentar un planteamiento orientado a reconocer tensiones o conflictos presentes entre dinámicas económico sociales y solidarias con dinámicas de mercado capitalista, antes que apreciar de manera separada y desconectada ambos campos. Asunto crucial en el marco del debate sobre los circuitos económico solidarios, porque se considera que no solo representan «espacios complejos de intercambio de servicios, bienes e incluso saberes que tienen como objeto, de una manera u otra significarse como alternativas tangibles y reales al mercado capitalista en general» (Arcos, 2018, p. 9) o donde es posible:

[R]econocer la presencia de universos económicos, en los cuales existen actos desinteresados, materializados en prácticas que, aún con los tropiezos y las deformaciones que se presentan en la práctica de algunas empresas, recogen nuevas maneras de relaciones económicas y sociales, basadas en la autogestión colectiva, solidaria y democrática que ponen en escena una ética solidaria, es decir, un voluntad, una conciencia y unos sentimientos que conducen a actuar con los demás de una manera más humana y reconociendo la ínter subjetividad. (Lopera y Mora, 2009, p. 92)

Sino que incluyen necesariamente - como en las estrategias antes mencionadas - relaciones basadas en racionalidades donde la solidaridad, la cooperación, la reciprocidad, están presentes; pero que no logran reemplazar la lógica del mercado capitalista, sino que conviven con ella y establecen, en más de un caso, relaciones de tensión. Asunto pertinente de considerar sobre todo si como señala Jiménez (2016), el concepto de los circuitos económicos solidarios interculturales - planteamiento trabajado desde el Movimiento de Economía Social y Solidaria del Ecuador- es:

[U]na propuesta conceptual-metodológica estratégica para el fomento de un sistema económico solidario que fomente el Sumak Ally Kawsay desde los territorios, los cuales puedan disputar sentidos, pero también flujos de la economía real y monetaria para disminuir el poder hegemónico de una sociedad de mercado y la construcción de una sociedad con mercado. (2016, p. 111)

Esta «sociedad con mercado» parece abre la posibilidad para reconocer las tensiones y conflictos que supone el despliegue de relaciones basadas en racionalidades donde la solidaridad, la cooperación, la reciprocidad, están presentes, sin negar mecanismos propios del mercado capitalista.

La necesidad de esto último radica en no perder de vista que el anclaje en el territorio y el despliegue de procesos económico sociales autogestionados y autocentrados, o con un fuerte protagonismo de mujeres, jóvenes, pueblos originarios (Urretabizkaia y Fernández-Villa, 2015) u otros sectores sociales, no están divorciados de la racionalidad del mercado capitalista o contextos globalizados e intercambios a escala mundial donde procesos de producción, 
comercialización y consumo, involucran relaciones donde esta racionalidad está presente; pero que no implica la ausencia del Estado y mucho menos la negación de la sociedad, su capacidad de ejercer control del Estado y el mercado, producir formas de autoridad sustentadas en el autogobierno y la democracia directa o reinventar relaciones económico sociales soportadas en la reciprocidad y la comunidad.

\section{NOTAS}

1 La cooperativa está ubicada en el distrito de Pangoa, provincia de Satipo, región Junín. El distrito de Pangoa posee una extensión de 6197 kilómetros cuadrados y una población - según el Instituto Nacional de Estadística e Informática (2018a; 2018b) - de 54.240 habitantes (2018a, p. 412), distribuidos en aproximadamente 174 centros poblados, incluidas 47 comunidades de pueblos originarios, 33 asháninkas y 14 nomatsiguengas (2018b: 98 y 108). Además, el distrito de Pangoa, junto al distrito vecino de Mazamari, concentran la mayor extensión de superficie cultivada de café en el Perú, al poseer de manera conjunta 23.223 hectáreas, que representan alrededor del $5 \%$ del total cultivable con el que cuenta el país (Díaz y Willems, 2017, p. 15).

2 Coraggio (2011) señala: «La economía social y solidaria es una forma de producir sociedad y no solo utilidades económicas, porque genera valores de uso para satisfacer necesidades de los mismos productores o de sus comunidades - generalmente de base territorial, étnica, social o cultural-y no está orientada por la ganancia y la acumulación de capital sin límites. Vuelve a unir producción y reproducción, al producir para satisfacer de manera más directa y mejor las necesidades acordadas como legítimas por la misma sociedad [...]. Su fundamento es, sin duda, el trabajo y el conocimiento encarnado en los trabajadores y sus sistemas de organización» (2011, pp. 45-46).

3 Tomado de http://cacpangoa.com

4 Parece pertinente indicar que la Cooperativa Agraria Cafetalera Pangoa es una cooperativa de usuarios o servicios para compras conjuntas, acceso al mercado, crédito, servicios educativos, etc. Los propietarios, en este caso, son los socios que hacen uso de los servicios que ella brinda.

5 El comercio justo - según la Coordinadora Latinoamericana de Comercio Justo- es un movimiento social global que busca promover patrones productivos y comerciales responsables y sostenibles, así como oportunidades de desarrollo para los pequeños agricultores, campesinos y artesanos en desventaja económica y social, respecto a los actores dominantes en el mercado. Ver http://clac-comerciojusto.org/ comercio-justo/introduccion/comercio-justo

6 Información tomada del cuadro acumulativo de la prima del comercio justo, 2003 al 2016, de la Cooperativa Agraria Cafetalera Pangoa.

7 Información proporcionada por Virgilio García Veli, responsable del área de industrias alimentarias de la cooperativa, a través de una entrevista telefónica realizada el 20 de septiembre de 2020.

$8 \mathrm{El}$ artículo surge del estudio de impacto del comercio justo en la Selva Central del Perú, realizado por el autor entre los años 2017 y 2018, por encargo de la Coordinadora Latinoamericana de Comercio Justo. 9 Los estudios sobre cooperativas de usuarios o servicios de productores agrarios cafetaleros han sido varios y no son nuevos en la investigación de las ciencias sociales y la ciencia económica en el Perú. Se puede recordar como referencia el trabajo de Fernández (1974), uno de los primeros, enfocado en las cooperativas cafetaleras de la Selva Central. La indagación, posteriormente, fue continuada por autores como Gálvez (1985), Barrenechea (1986) o Lazarte (1988). Durante los noventa, Paz (1998) y Junta Nacional del Café (1999), continúan esta labor de análisis. Indagaciones posteriores han estado dedicadas al examen de su dinámica actual e incluyen, entre otros, estudios como el de Remy (2007), centrado en su aporte empresarial; o Pérez (2007), interesado en las relaciones de género. La pesquisa de La Serna (2010), por su parte, aborda la recuperación de la memoria histórica del cooperativismo cafetalero de la Selva Central. Sancho y Calderón (2013), analizan la relación entre el pueblo asháninka y la cooperativa 
Kemito. Otros han intentado brindar miradas más sistemáticas, como el trabajo colectivo de Mogrovejo, Vanhuynegem, Vásquez (2012), orientado a sustentar la idea de «renacimiento del modelo cooperativista peruano»; o proponer un diagnóstico del sector, como el realizado por Díaz y Willems (2017); o sobre grupos específicos, con los jóvenes de cooperativas cafetaleras, trabajado por Rikolto (2017). El estudio del impacto del comercio justo y su relación con experiencias cooperativistas en territorios específicos está en pleno proceso de exploración. No han sido hasta ahora muchos los estudios realizados, Cycon (2007) y Fort y Ruben (2008), figuran entre los primeros. Barriga (2009), indaga en el caso de la Cooperativa Maranura y la central de cooperativas CocLA, en La Convención, Cusco; Keisling (2013), analiza de manera crítica el comercio justo, a partir del abordaje, igualmente, del caso de La Convención; Aguilar y Flores (2015), abordan el caso de la Cooperativa Chaco Huayanay, también ubicada en La Convención; Pujay (2017), estudia el microcrédito y su relación con las redes de comercio justo, en la Cooperativa Agraria Cafetalera Pangoa, Satipo, Junín; Guzmán y otros (2017), estudian el caso de la central de cooperativas CecovasA, de Sandia, Puno; Chagua y Zuñiga (2018), trabajan de manera integral el caso de la Cooperativa Agraria Cafetalera Pangoa.

10 Marino Narváez Soto, agrónomo formado en la Universidad Nacional del Nordeste, provincia de Santa Fe, Argentina, en 1954; secretario del comité organizador y primer gerente de la Cooperativa Agraria Cafetalera Pangoa, propone que el origen de la cooperativa está ligada a dos instituciones claves en la historia de la Selva Central y la región Junín: la Universidad Nacional del Centro y el movimiento cooperativista. Él fue entrevistado en dos oportunidades: el 28 de septiembre y el 20 de octubre de 2017. 11 Julio Pablo Aysana Caynicela, socio de la cooperativa desde 1978 y dirigente en varios momentos de ella, fue entrevistado el 14 de octubre de 2017.

12 Idea tomada de la entrevista realizada a Percy Clemente, socio e integrante del comité de vigilancia de la cooperativa en estos años, el 15 de enero de 2019.

13 El relato se lo tomó de la entrevista con Olinda Vilcahuamán, secretaria de la cooperativa, realizada el 13 de octubre de 2017 .

146.896 quintales, $83 \%$, son colocados en mercados capitalistas locales y nacionales como la selva central o la ciudad de Lima; y una pequeña cantidad, 375 quintales, 5\%, en el mercado de café orgánico. Información recogida del historial de ventas de café, 2003 al 2018, de la Cooperativa Agraria Cafetalera Pangoa. 15 Ídem.

16 Información tomada del cuadro acumulativo de la prima del comercio justo, 2003 al 2016, de la Cooperativa Agraria Cafetalera Pangoa.

17 Otras organizaciones necesarias de mención, vinculadas a las mismas redes, son: Twin trading, Falcon Commodity, de Inglaterra; Cooperatives Coffee, Paragon Coffee, Royal Coffee, Central Coffee, Convencional Paragon Coffee, de Estados Unidos; Level ground, Just Us, de Canada; Saldac, Francia; entre otras. Información tomada de Cooperativa Agraria Cafetalera Pangoa (2017, p. 17).

18 Se anota que la cooperativa, el 2018, vende al comercio justo 9459 quintales de grano de café orgánico y 2890 quintales de grano de café convencional. Información recogida del historial de ventas de café, 2003 al 2018, de la Cooperativa Agraria Cafetalera Pangoa.

19 Información recogida del historial de ventas de café, 2003 al 2018, de la Cooperativa Agraria Cafetalera Pangoa.

20 Información tomada del cuadro acumulativo de la prima del comercio justo, 2003 al 2016, de la cooperativa. 21 Información brindada por la gerencia de la Cooperativa Agraria Cafetalera Pangoa.

22 Ídem.

23 Ídem.

24 Ídem.

25 Las entrevistas fueron realizadas entre octubre y diciembre de 2017. Algunos entrevistados señalaban que los servicios brindados por la cooperativa los hacían «sentir parte de una familia donde todos se cuidaban mutuamente».

26 Rolando Aparco Belito fue entrevistado el 14 de octubre de 2017. 


\section{REFERENCIAS}

Aguilar Loyola, E. Y. y Flores Mostacero, K. W. (2015). Impacto de la práctica comercial justa fairtrade del comercio internacional, en el desarrollo socio-económico de las familias cafetaleras de la Cooperativa Chaco Huayanay en La Convención-Cusco, período 2010 al 2014. (Tesis para optar el título profesional de Administrador y Negocios Internacionales). Trujillo: Facultad de Negocios de la Universidad Privada del Norte.

Arcos Alonso, A. (2018). Circuitos económicos (ecosistemas) locales de economía social y solidaria. Una herramienta para un desarrollo humano sostenible y la inclusión social. Ponencia presentada al XVII Congreso Internacional de Investigadores en Economía Social y Cooperativa. La economía social: transformaciones recientes, tendencias y retos de futuro, organizado el 4 y 5 de octubre en la ciudad de Toledo, por ciriec y la Universidad Castilla La Mancha.

Barrenechea, C. (1986). Café: problemática y alternativas. Centro Peruano de Estudios Sociales (CEPEs). Barriga, P. (2009). Funcionamiento de cooperativas cafetaleras y su impacto en la vida familiar de sus asociados: casos de familias de dos sectores de la provincia de La Convención vinculadas a la Cooperativa Maranura y a la central de cooperativas cocla. (Tesis para optar la licenciatura en Antropología). Lima: Pontificia Universidad Católica del Perú.

Cooperativa Agraria Cafetalera Pangoa (2017). Conociendo a nuestra CAC Pangoa Ltda. Cooperativa Agraria Cafetalera Pangoa.

Coraggio, J. L. (2011). La economía social como vía para otro desarrollo social. En A. Acosta y E. Martínez (eds.), José Luis Coraggio. Economía social y solidaria. El trabajo antes que el capital. Ediciones Abya-Yala.

Cycon, D. (2007). Javatrekker: Dispatches from the world of fair trade coffee. Chelsea Green Publishing.

Chagua Vicuña, K. S. y Zúñiga Gabancho, K. (2018). Impacto del comercio justo en el desarrollo socio-económico de los socios de la Cooperativa Agraria Cafetalera Pangoa Ltda. en el periodo 2015-2016. (Tesis para optar el título profesional de Licenciado en International Business). Lima: Facultad de Ciencias Empresariales de la Universidad San Ignacio de Loyola.

Díaz Vargas, C. y Willems, M. C. (2017) Línea de base del sector café en el Perú. Programa de las Naciones Unidas para el Desarrollo.

Fernández Arroyo, A. M. (1974). Las cooperativas cafetaleras en la Región Central de la Selva Alta. (Tesis para optar el grado de Bachiller en Sociología). Lima: Universidad Nacional Mayor de San Marcos.

Fort, R. y Ruben, R. (2008b). The impact of fair trade certification on coffee producers in Peru. En R. Ruerd (ed.), The impact of fair trade. Wageningen University.

Gálvez, I. (1985). Diagnóstico del sistema cafetalero peruano. Universidad del Pacífico.

Guzmán Nina, A., Lazo Cañete, K., Rupay Quispe, M., Guadalupe Romero, M. y Gómez Pérez, V. (2017). La economía social y solidaria de la Central de Cooperativas Agrarias Cafetaleras de los Valles de Sandia. En L. Montoya (ed.), ¿Otras economías? Experiencias económico sociales y solidarias en el Perú. Universidad Nacional Mayor de San Marcos, Facultad de Ciencias Sociales, Seminario de Economía Social, Solidaria y Popular; Hegoa Instituto de Estudios sobre Desarrollo y Cooperación Internacional, Universidad del País Vasco.

Instituto Nacional de Estadística e Informática (2018a). Resultados definitivos de los censos nacionales 2017, Junín. XII de población, VII de vivienda y III de comunidades indígenas. Instituto Nacional de Estadística e Informática. 
Instituto Nacional de Estadística e Informática (2018b). Resultados definitivos del III Censo de comunidades nativas 2017. Instituto Nacional de Estadística e Informática.

Jiménez, J. (2016). Movimiento de economía social y solidaria de Ecuador. Circuitos económicos solidarios interculturales. Revista de la Academia, 21, (s. d.).

Junta Nacional del Café (1999). El café peruano y sus desafíos en el tercer milenio. Junta Nacional del Café.

Keisling, K. (2013). La realidad de comercio justo: una investigación de las fallas y los éxitos del sistema en el valle de La Convención, Perú, desde la perspectiva de los productores. En Independent Study Project (ISP) Collection 1657.

La Serna Salcedo, J. C. (2010). De golondrinos y enganches a empresarios exportadores. Historia del café y el cooperativismo cafetalero en la selva central. Junta Nacional del Café.

Lazarte, J. (1988). Café: Problemas y propuestas. Debate agrario, (3), (s. d.).

Lopera García, L. D. y Mora Rendón, S. B. (2009). Los circuitos económicos solidarios: espacio de relaciones y consensos. Semestre Económico, 12(25), (s. d.).

Mogrovejo, R., Vanhuynegem, P. y Vásquez, M. (2012). Visión panorámica del sector cooperativo en Perú. El renacimiento de un modelo. oIt, Oficina de la oit para los Países Andinos.

Montoya, L., Alva, M., Carcelén, C., Pérez, E. y Cardeña, E. (2018). Desarrollo e implementación de estrategias económico alternativas en contextos de desastre socionatural en Perú. Informe Académico de Proyectos de Investigación con Financiamiento para Grupos de Investigación, Vicerrectorado de Investigación y Posgrado, Universidad Nacional Mayor de San Marcos.

Paz López, S. (1998). La producción de café orgánico en la sierra de la Región Grau. Cuadernos Andinos, (9), (s. d.).

Pérez Alva, E. (2007). Productoras de café y cacao actoras del desarrollo rural con equidad. Coordinadora Nacional de la Mujer Productora de Café y Cacao Junta Nacional del Café.

Pujay Sobrado, Y. (2017). Una experiencia de microcréditos solidario: El Comité de Desarrollo de la Mujer de la Cooperativa Agraria Cafetalera Pangoa. En. L. Montoya (ed.), ¿Otras economías? Experiencias económico sociales y solidarias en el Perú. Universidad Nacional Mayor de San Marcos, Facultad de Ciencias Sociales, Seminario de Economía Social, Solidaria y Popular; Hegoa Instituto de Estudios sobre Desarrollo y Cooperación Internacional, Universidad del País Vasco.

Rikolto (2017). Café y cacao con sabor a jóvenes. Un estudio sobre la juventud rural en café y cacao en Perú. Rikolto.

Remy, M. I. (2007). Cafetaleros empresarios. Dinamismo asociativo para el desarrollo en el Perú. Instituto de Estudios Peruanos, Oxfam Internacional.

Sancho Ferrer, A. y Calderón Pacheco, L. A. (2013). Kemito Ene: asociación, producción y mercado entre los asháninka del río Ene. Deutsche Gesellschaft für Internationale Zusammenarbeit (GIZ), Proyecto de Conservación de Bosques Comunitarios (СвC).

Urretabizkaia, L. y Fernández-Villa, M. (2015). Circuitos económicos solidarios interculturales y su contribución a los derechos económicos de las mujeres: el caso de Loja. Hegoa Instituto de Estudios sobre Desarrollo y Cooperación Internacional, Universidad del País Vasco. 